\title{
Salmonelose septicêmica prolongada associada à esquistossomose: evolução do conhecimento e mecanismos imunopatogênicos
}

\author{
Schistosoma-associated chronic septicemic salmonellosis: evolution \\ of knowledge and immunopathogenic mechanisms
}

\author{
Maria Imaculada Muniz-Junqueira', Carlos Eduardo Tosta ${ }^{1}$ e Aluízio Prata ${ }^{2}$
}

\begin{abstract}
RESUMO
A salmonelose septicêmica prolongada é uma entidade clinicamente individualizada caracterizada por febre prolongada com hepatoesplenomegalia que ocorre em indivíduos esquistossomóticos coinfectados com salmonelas. Os mecanismos imunopatogênicos são vários e dependem das peculiaridades das interações entre as salmonelas e várias espécies do gênero Schistosoma. As modificações ocasionadas no sistema imunitário pela infecção parasitária são responsáveis pela evolução do quadro da doença. Nesta revisão, analisamos a evolução do conhecimento sobre a entidade e discutimos os possíveis mecanismos imunofisiopatogênicos que concorrem para seu desenvolvimento.
\end{abstract}

Palavras-chaves: Salmonelose septicêmicas prolongada. Esquistossomose. Salmonella. Fagocitose. Monócitos.

\begin{abstract}
Chronic septicemic salmonellosis is an individualized clinical entity characterized by prolonged fever with enlargement of the liver and spleen that occurs in Schistosoma-infected individuals who are coinfected with Salmonella. Several immunopathogenic mechanisms are involved, and they depend on the peculiarities of the interactions between Salmonella and various species of the genus Schistosoma. The modifications to the immune system that are caused by parasite infection are responsible for the evolution of the disease. In this review, we analyze the evolution of the knowledge on this entity and discuss the possible immuno-physiopathogenic mechanisms that contribute towards its development.
\end{abstract}

Key-words: Chronic septicemic salmonellosis. Schistosomiasis. Salmonella. Phagocytosis. Monocytes.

A salmonelose septicêmica prolongada constitui entidade clínica caracterizada por febre irregular prolongada e hepatoesplenomegalia, decorrente da coinfecção por salmonelas em indivíduos com esquistossomose. 0 quadro clínico difere tanto das manifestações da esquistossomose isoladamente, quanto daquele associado somente à infecção por salmonelas patogênicas, resultando em uma entidade clínica individualizada ${ }^{99}$.

\section{QUADRO CLÍNICO}

A salmonelose septicêmica prolongada acomete preferencialmente jovens entre 10 e 30 anos e se manifesta por febre, perda de peso e fadiga. Embora os

\footnotetext{
1. Laboratório de Imunologia Celular, Patologia, Faculdade de Medicina, Universidade de Brasília, Brasília, DF. 2. Disciplina de Doenças Infecciosas e Parasitárias, Universidade Federal do Triângulo Mineiro, Uberaba, MG.

Endereço para correspondência: Profa. Maria Imaculada Muniz-Junqueira. Laboratório de Imunologia Celular/FM/ UnB, Campus Darci Ribeiro, Asa Norte, 70.910-900 Brasília, DF

Fax: $5561 \quad 3273-3907$

e-mail: mimjunqueira@unb.br

Recebido para publicação em 08/01/2009

Aceito em 20/07/2009
}

indivíduos acometidos, geralmente, apresentarem-se muito emagrecidos e com um quadro de bacteremia com meses de duração, não aparentam estar toxemiados. 0 início da doença é insidioso e a febre, que se prolonga por muitos meses, é irregular. A hepatoesplenomegalia geralmente é pronunciada, com o baço frequentemente ultrapassando a cicatriz umbilical 35997125127 .

0 comprometimento do estado geral se acentua com o tempo e as mucosas descoradas, o emagrecimento e a perda de massa muscular expressam a decadência física do paciente. Entretanto, apesar do intenso comprometimento físico, os indivíduos acometidos geralmente continuam com suas atividades laborais normais. E, mesmo quando o agente etiológico é a Salmonella typhi, diferentemente do quadro de febre tifóide, os pacientes não se apresentam torporosos e nem mostram sintomatologia que signifique comprometimento do sistema nervoso central ${ }^{88} 128.0$ abdome geralmente é distendido, diarréia e dor abdominal são muito frequentes, sendo comum a presença de sangue e muco nas fezes ${ }^{125}$. As manifestações cutâneas são menos frequentes, embora se deva destacar a presença de petéquias, ocorrendo em aproximadamente 50\% dos casos. Localizam-se geralmente em membros inferiores, abaixo dos joelhos, principalmente na região maleolar. Aparecem em surtos cíclicos que se repetem por todo o curso da doença. Edema de membros inferiores também é frequente $8^{8725128}$. 


\section{CARACTERIZAÇÃO DA SÍNDROME}

A primeira referência da associação entre esquistossomose e febre tifóide foi feita em 1951, por Hsü e Hsü, que relataram 11 casos da doença na China, conforme referência de Tai e cols ${ }^{124}$. Três anos depois, em 1954, a síndrome foi documentada por Ferreira, em São Paulo, Brasil, que verificou que a infecção por Salmonella typhi exibia um quadro clínico-evolutivo diferente e peculiar quando instalada em pacientes portadores de esquistossomose mansoni ${ }^{30}$. Em 1959, Teixeira ${ }^{125}$, em Salvador, apresenta nova observação confirmando a existência de uma forma peculiar de salmonelose, caracterizada por infecção septicêmica de curso prolongado, em pacientes esquistossomóticos. A presença de bacteremia prolongada por salmonelas em indivíduos acometidos foi definitivamente demonstrada por Neves, em $1967^{87}$, que detectou a presença persistente da bactéria na corrente sanguínea por até 113 dias, por meio de hemoculturas seriadas. Embora vários sorotipos de Salmonella tenham sido descritos associados à síndrome, não foi possível relacioná-los com diferenças nas alterações clínicas observadas, que apresentam grande uniformidade ${ }^{90}$. Posteriormente, outras enterobactérias, como a Escherichia coli ${ }^{129}$ e a Shigella ${ }^{127}$, também foram responsabilizadas por quadros clínicos indistinguíveis daqueles determinados pelas salmonelas em pacientes esquistossomóticos.

Pelos estudos clínicos realizados em São Paulo, Bahia e Minas Gerais ficou caracterizado que os indivíduos coinfectados com Salmonella typhi e Schistosoma mansoni apresentavam, em sua grande maioria, a forma hepatoesplênica da esquistossomose e mostravam um quadro clínico de febre com calafrios que podia durar meses, com perda de peso e hepatoesplenomegalia acentuadas $^{31} 888999107$ 127. Esse quadro clínico diferia do quadro clássico da febre tifóide ${ }^{27} 3045 \mathrm{e}$ da septicemia por bacilos Gramnegativos, assemelhando-se mais às infecções que acometem o sistema de fagócitos mononucleares, tal como o calazar88 89126.

o quadro clínico de febre prolongada e hepatoesplenomegalia associadas à salmonelose septicêmica prolongada foi descrito em associação com a esquistossomose causada pelas principais espécies de esquistossomas que infectam o homem: o Schistosoma mansoni ${ }^{31} 89107$, o Schistosoma japonicum ${ }^{124}$, o Schistosoma haematobium $^{41}$ e o Schistosoma intercalatum ${ }^{35}{ }^{36}$. Na esquistossomose por Schistosoma haematobium, observa-se mais frequentemente a presença persistente de salmonela em uroculturas repetidas ${ }^{39} 426062$; porém, quadro clínico semelhante ao da enterobacteriose septicêmica prolongada também foi descrito ${ }^{41}$.

Os indivíduos acometidos apresentam, usualmente, boa resposta à terapêutica antibacteriana, entretanto as recaídas são frequentes enquanto não se elimina concomitantemente 0 esquistossoma ${ }^{90} 107$. Já foi descrita, inclusive, a cura da salmonelose pelo tratamento exclusivo da esquistossomose ${ }^{5666}$.

\section{MECANISMOS FISIOPATOGÊNICOS}

Interação Schistosoma-Salmonella. A par dessas observações clínicas, interessantes relatos de associação entre espécies do gênero Schistosoma e diferentes bactérias têm sido publicados. A associação entre Schistosoma e bactérias já era conhecida desde 1940, pela descrição de Krakower e cols ${ }^{55}$ que observaram a presença de bactérias Gram-positivas no ceco do Schistosoma mansoni em cortes histológicos de fígado de animais esquistossomóticos. Rocha e cols, em 1971 ${ }^{110}$, cultivaram Salmonella typhi de esquistossomas recolhidos do sistema porta de camundongos esquistossomóticos submetidos à infecção por esta bactéria. Além disso, Ottens e Dickerson, em $1972^{95}$, observaram a colonização do ceco de roedores e primatas portadores de Schistosoma mansoni e Schistosoma matthei quando inoculados por bactérias Gram-negativas, sendo que estas bactérias apresentaram nítido efeito esquistossomicida.

Em indivíduos portadores de salmonelose septicêmica prolongada determinada por Salmonella paratyphi A, Young e cols ${ }^{139}$ mostraram a presença da bactéria associada ao tegumento do esquistossoma. Objetivando investigar este fenômeno, Lo Verde e cols ${ }^{65}$ utilizaram cepa de Salmonella typhimurium que não expressava pili e vermes com a abertura do aparelho digestivo ligada para demonstrar a importância da presença de pilus para a aderência da bactéria ao tegumento do parasito. Em reforço a esta observação, Melhem e Lo Verde ${ }^{71}$ mostraram que 0 tratamento prévio de Salmonella typhimurium com anticorpos anti-pili bloqueava a aderência da Salmonella à superfície do esquistossoma. Esses autores mostraram também que a ligação dos pili é específica e devida a receptores semelhantes aos de manose na superfície do verme. Entretanto, a importância da presença de pilus sobre a evolução da esquistossomose não foi comprovada por Tuazon e cols ${ }^{130}$ em estudos in vivo. Esses autores observaram que não havia alteração da mortalidade de camundongos esquistossomóticos, independentemente de serem infectados com cepas de Salmonella typhimurium com ou sem pili. Por outro lado, Delaunay-Chaillou e cols ${ }^{24}$ mostraram que determinados anticorpos específicos para salmonela facilitavam a ligação da mesma ao tegumento do esquistossoma. Bouillard e cols ${ }^{10}$ utilizaram observação por microscopia eletrônica de varredura para sugerir que a adesão de Salmonella typhimurium ao tegumento do esquistossoma ocorre devido à síntese pela bactéria de fibras que penetram no tegumento do helminto.

Experimentalmente, também, constatou-se que a salmonela pode associar-se às três espécies de esquistossomas mais importantes que afetam o homem: Schistosoma mansoni, Schistosoma haematobium e Schistosoma japonicum ${ }^{65}$. Essa associação se verifica também em camundongos esquistossomóticos, nos quais ocorre bacteremia por tempo mais prolongado quando da infecção com Salmonella e que exibem maior mortalidade do que os controles não parasitados ${ }^{79}$ 106111. Tais observações levaram à interpretação de que a presença do Schistosoma e sua peculiar interação com as salmonelas são essenciais para a instalação e o desenvolvimento da salmonelose septicêmica prolongada.

Infecção esquistossomótica. Estima-se que a esquistossomose afete cerca de 200 milhões de pessoas residentes, predominantemente, em áreas rurais de dezenas de países 
subdesenvolvidos, onde predominam a pobreza, a ignorância, as moradias inadequadas, as práticas de higiene impróprias e a deficiência de saneamento básic $0^{5396137}$. Por essas características sócio-econômico-culturais, infere-se que as condições das regiões onde prevalece a esquistossomose são também altamente propícias à contaminação pelas salmonelas ${ }^{2744}$. No entanto, a frequiência de salmonelose septicêmica prolongada, clinicamente manifesta, é muito menor que a esperada nas regiões endêmicas para esquistossomose, considerando-se o risco permanente de exposição às salmonelas a que ficam submetidos os indivíduos esquistossomóticos ${ }^{127}$. Ademais, a infecção bacteriana incide e prevalece quase exclusivamente em indivíduos que apresentam a forma hepatoesplênica de esquistossomose ${ }^{105}$, principalmente adolescentes e adultos jovens ${ }^{88} 126$, condição esta nem sempre associada com as maiores cargas parasitárias ${ }^{700} 101102$. Portanto, seria de se esperar que a salmonelose septicêmica prolongada fosse diagnosticada com maior frequência nas áreas endêmicas da esquistossomose. Uma explicação alternativa para a baixa frequência da coinfecção clinicamente manifesta em áreas endêmicas seria que a maioria dos pacientes esquistossomóticos expostos às salmonelas apresentasse quadro clínico discreto ou que a instalação e o desenvolvimento das manifestações clínicas da salmonelose septicêmica prolongada não dependessem somente da presença do esquistossoma e da salmonela no sistema venoso do paciente. Outros fatores poderiam estar concorrendo para a instalação e/ou o desenvolvimento da síndrome bacteriêmica, como por exemplo, deficiências do sistema imunitário, que podem ocorrer em alguns pacientes esquistossomóticos. De fato, presença de infecção subclínica por salmonela foi sugerida pela observação de níveis séricos elevados de anticorpos para 0 antígeno $0 \mathrm{da}$ bactéria em pacientes esquistossomóticos, sem que expressassem manifestação clínica da salmonelose septicêmica prolongada ${ }^{82} 84$. Esta interpretação decorre do fato de que os anticorpos para o antígeno 0 são imunoglobulinas da classe M (IgM), o que sugere, portanto, infecção presente ou recente pela bactéria.

Além da presença do esquistossoma e da salmonela no hospedeiro com a síndrome bacteriêmica prolongada, outros possíveis fatores determinantes associados precisam ser considerados entre os mecanismos fisiopatogênicos. Para isto é importante analisar os mecanismos de imunidade para a salmonela e as alterações do sistema imunitário decorrentes da infecção pelo esquistossoma.

Infecção por Salmonella. 0 curso da infecção por salmonela em indivíduos hígidos é determinado por muitos fatores, incluindo a carga bacteriana, o sorotipo, a virulência e a capacidade invasiva das bactérias, além de fatores relacionados à resistência do hospedeiro, particularmente os de natureza imunológica $^{44}$.

As diferentes espécies de Salmonella apresentam acentuada variabilidade em sua capacidade patogênica, que pode se manifestar desde uma infecção intestinal leve com insignificante invasão da corrente sanguínea, como a determinada pela Salmonella anatum, até infecções localizadas com bacteremia, como a produzida pela Salmonella cholerasuis ${ }^{44}$, ou mesmo o quadro septicêmico causado pela Salmonella typhi ${ }^{27}{ }^{45}$. Independentemente da espécie de salmonela, todas podem causar quadro clínico semelhante de salmonelose septicêmica prolongada no hospedeiro esquistossomótic $0^{90}$.

Entre os fatores relacionados ao hospedeiro humano, identificados como importantes na maior ou menor resistência à infecção por salmonelas, incluem-se a idade, a presença de uma flora intestinal equilibrada e a concomitância de certas doenças ${ }^{44}$. Particularmente, com respeito a este último fator, diversas condições clínico-patológicas que comprometem o funcionamento do sistema imunitário predispõem à infecção por vários patógenos, entre os quais as salmonelas, como a cirrose hepática ${ }^{20}{ }^{44}$, doenças neoplásicas ${ }^{44} 136$, imunossupressão associada a transplantes ${ }^{114}$, síndrome da imunodeficiência adquirida $^{3238}{ }^{85}$, entre outras ${ }^{164}$. Aproximadamente, metade dos indivíduos com bacteremias por salmonelas apresenta doenças predisponentes $^{1644}$. Assim, parece haver relação entre disfunção do sistema imunitário e o desenvolvimento de salmonelose sistêmica em portadores de algumas doenças concomitantes. As alterações do sistema imunitário nessas condições clínicas incluem deficiências do sistema do complemento, alterações do sistema de fagócitos e da resposta imunitária celular ${ }^{32} 404485$ ${ }^{114} 136.0$ indivíduo esquistossomótico tem em comum com os portadores daquelas condições patológicas a predisposição à salmonelose sistêmica. Entretanto, diferentemente do que ocorre com aqueles pacientes, esta predisposição é predominantemente para infecções por salmonelas, embora possa ocorrer também maior susceptibilidade para infecções por outras enterobactérias e bactérias Gram-positivas ${ }^{57}$. Interessantemente, os indivíduos esquistossomóticos não apresentam maior susceptibilidade a outros patógenos que são tão frequentes em pacientes imunodeficientes. Entretanto, tais indivíduos também apresentam dificuldade para erradicar o vírus B da hepatite ${ }^{5716} \mathrm{e}$, estudos em modelos experimentais mostram maior susceptibilidade dos animais esquistossomóticos a Plasmodium berghei ${ }^{138}$, Leishmania mexicana ${ }^{17}$, Trypanosoma cruzij $^{2}$ e Entamoeba histolytica ${ }^{54}$. Também tem sido descrita maior suscetibilidade de pacientes esquistossomóticos e animais de experimentação para apresentar abscesso hepático por Staphylococcus aureus ${ }^{57} 58$ 59. Quadro clínico semelhanteao apresentado por indivíduos esquistossomóticos com salmonelose septicêmica prolongada foi observado numa paciente com septicemia prolongada por Salmonella enteriditis portadora de doença granulomatosa crônica da infância, na qual se demonstrou deficiência dos fagócitos para a salmonela ${ }^{75}$. Esses fatos sugerem que vários fatores devem estar associados para que ocorra expressão clínica da síndrome da salmonelose septicêmica prolongada.

Diversas pesquisas em camundongos procuraram determinar como se processa a resistência às salmonelas no hospedeiro hígido. Mackaness e cols ${ }^{68}$ mostraram que camundongos normais desenvolviam resistência à Salmonella typhimurium e que o soro imune facilitava a retirada da bactéria da corrente sanguínea, sem, no entanto, ser responsável pelo desenvolvimento da imunidade, que depende da resposta de linfócitos TCD $4^{+21140}$. Collins e cols $^{19}$ verificaram a necessidade da persistência da bactéria no organismo do hospedeiro por algum tempo para que se 
processasse 0 desenvolvimento efetivo de proteção. Blanden e $\operatorname{cols}^{8}$ mostraram que a resistência adquirida se desenvolve a medida que se desenvolve 0 aumento da capacidade bactericida dos macrófagos. Além disso, o tratamento dos animais com sílica, que é tóxica para macrófagos, aumenta a patogenicidade das bactérias ${ }^{134}$.

0 desenvolvimento de proteção conferida por vacina com salmonelas vivas se associa ao aparecimento de hipersensibilidade retardada, a qual decorre do estabelecimento de imunidade celular ${ }^{51}$. Nas fases iniciais, a proteção conferida pela imunização com bacilos vivos deve-se à função de macrófagos e, nas fases tardias, à capacidade dos linfócitos T apresentarem uma resposta proliferativa aos antígenos da salmonela. Esta proteção é transferida por linfócitos $T^{51121140}$.

As salmonelas são geralmente fagocitadas por macrófagos quando inoculadas em animais sadios ${ }^{196468} 123134$. No entanto, a capacidade bactericida dessas células varia em função das características da salmonela ${ }^{19} \quad 4774134$. A maior parte das salmonelas é destruída logo após a fagocitose, entretanto, algumas horas após, as que não foram destruídas voltam a se multiplicar no interior dos macrófagos ${ }^{47} 7^{74}$. As salmonelas avirulentas são mais facilmente destruídas que as virulentas ${ }^{4774} \mathrm{e}$ as cepas flageladas mostram-se mais resistentes do que as não flageladas $^{134}$. Em animais que já haviam tido contato prévio com os bacilos vivos, a capacidade bactericida dos macrófagos mostrou-se aumentada $a^{47} 74$. Por outro lado, a fagocitose realizada em presença de soro imune não potenciou a inibição do crescimento bacteriano intracelular ${ }^{74}$. A resistência inata à infecção por salmonela é geneticamente determinada, sendo o macrófago a célula efetora dessa imunidade ${ }^{649298119123}$. No caso da Salmonella typhi, a resistência inata à infecção também foi relacionada à falta de nutrientes essenciais para a bactéria no hospedeiro resistente ${ }^{91}$.

Durante o período de estado da febre tifóide no homem há formação de anticorpos IgM, IgG e imunocomplexos na circulaçã̃o sanguínea, além de ocorrer consumo de complemento ${ }^{103} \mathrm{e}$ desenvolvimento de resposta imune celular ${ }^{46}{ }^{104}{ }^{132}$. Os pacientes com as formas mais graves da doença apresentam depressão da resposta imune mediada por linfócitos $\mathrm{T}^{104}$.

0 curso da infecção por salmonela em hospedeiro sem outras condições patológicas associadas é determinado por características próprias da bactéria, tais como a presença de flagelos ${ }^{134}$, necessidade de nutrientes essenciais ${ }^{91}$, capacidade de resistir à ação bactericida dos macrófagos ${ }^{4774} \mathrm{e}$ pelas peculiaridades da interação com o sistema imunitário do hospedeiro. Esta, em sua fase inicial, depende de mecanismos inespecíficos de defesa como a função dos fagócitos profissionais ${ }^{8192}$ que é facilitada pela presença de anticorpos ${ }^{68} \mathrm{e}$, na fase de erradicação das bactérias, depende do desenvolvimento de imunidade celular mediada por macrófagos ativados ${ }^{51}$. Assim, é importante entender as características da resposta imunitária do paciente esquistossomótico para se compreender as peculiaridades da salmonelose septicêmica prolongada.
Alterações da resposta imunitária na esquistossomose. $\mathrm{Na}$ grande maioria das vezes, a salmonelose septicêmica prolongada ocorre na forma crônica hepatoesplênica da esquistossomose, e nessa situação, o esquistossoma, alojado no sistema venoso do indivíduo, e seus ovos, são fontes constantes de estímulo antigênico para o sistema imunitário do hospedeiro. Esses antígenos estimulam o sistema imunitário resultando na produção de anticorpos específicos $\operatorname{IgM}_{\text {, }} \operatorname{IgG}^{6} 121386$ e $\operatorname{IgE}^{12} 2572$, com consequente formação de imunocomplexos ${ }^{49}{ }^{61120}$. Os antígenos e imunocomplexos são removidos da circulação sanguínea no fígado, pelas células de Kupffer, mas podem também ser depositados nos glomérulos renais ${ }^{59}{ }^{122}$. Além desses antígenos, os indivíduos esquistossomóticos em áreas de transmissão continuam sendo frequentemente reinfectados e, portanto, também submetidos a contatos com antígenos de cercárias. Contra essas são mobilizadas defesas do tipo citotoxicidade mediada por eosinófilos e macrófagos dependentes de anticorpos das classes $\operatorname{IgG}$ e $\operatorname{IgE} \mathrm{E}^{1415} 96$.

Os ovos, constantemente embolizados nos vasos présinusoidais hepáticos, estimulam tanto a imunidade humoral quanto a celular ${ }^{96122133}$, desencadeando a formação de granulomas ao redor dos ovos, fenômeno que se constitui em hipersensibilidade retardada dependente de linfócitos T ${ }^{96}{ }^{133}$, que, na fase inicial, é predominantemente do padrão T auxiliar $1 \mathrm{e}$, posteriormente, devido ao processo de imunorregulação, passam para o padrão T auxiliar $2^{96}$.

$\mathrm{Na}$ fase aguda da infecção esquistossomótica, os títulos de anticorpos estão muito elevados, bem como se encontram exacerbadas as respostas de hipersensibilidade retardada ${ }^{122}$. Com a cronicidade da infecção desenvolvem-se mecanismos imunomoduladores, diminuindo os níveis de anticorpos ${ }^{86}$ e a intensidade da resposta granulomatosa ${ }^{3} 9$ 133. Em decorrência desses mecanismos estabelece-se um estado crônico de imunodepressão celular ${ }^{70}{ }^{122}$, sendo que o número de linfócitos T no sangue periférico mostra-se diminuído ${ }^{67}$ ou normal ${ }^{21}$ e o de linfócitos B apresenta-se normal ${ }^{67}$.

A maioria dos estudos sobre a imunidade celular na esquistossomose tem avaliado a resposta proliferativa de linfócitos in vitro a antígenos específicos, mitógenos e antígenos não relacionados ao parasito. A reposta a antígenos dos ovos na fase crônica da infecção mostra-se na grande maioria das vezes deprimida ${ }^{5828113}$. Entretanto, na fase inicial da oviposição em pacientes com a forma hepatointestinal há uma grande porcentagem de indivíduos forte respondedores aos antígenos de ovos $^{1234}$. Enquanto que a reação aos antígenos das cercárias e dos vermes adultos pode ser normal ou deprimida 1828337793112113 , o mesmo acontecendo em relação aos mitógenos e aos antígenos não específicos 452128769397112113 .

Ainda está pouco esclarecida a relação entre o estado de imunidade celular e a forma clínica da doença e a carga parasitária. Ellner e cols ${ }^{28}$ mostraram que, em indivíduos com a forma hepatointestinal, a resposta proliferativa de linfócitos a antígenos do verme adulto mostrou-se deprimida naqueles com a carga parasitária elevada. Por outro lado, indivíduos com a forma hepatoesplênica apresentaram ou ausência de resposta aos antígenos do verme adulto 
ou resposta exacerbada. Nesses indivíduos, a resposta de linfócitos aos mitógenos e à estreptoquinase-estreptodornase manteve-se preservada. Aumento da produção de IL-10 e diminuição da produção de interferon- $\gamma$ também têm sido relacionados com 0 aumento da carga parasitária ${ }^{12}$.

Quando avaliada por meio de testes cutâneos de hipersensibilidade retardada, a resposta imune celular inespecífica mostra-se deprimida em pacientes esquistossomóticos tanto com a forma intestinal ${ }^{83}$ como hepatoesplênica ${ }^{22} 4383$ e em portadores de salmonelose septicêmica prolongada ${ }^{22}{ }^{43}$, sendo a deficiência observada mais frequentemente nos indivíduos com as formas clínicas mais graves da esquistossomose ${ }^{83}$ e pode ser revertida pela eliminação do parasito $^{81}$.

A imunopatogenia da esquistossomose tem sido muito estudada, particularmente nos aspectos relacionados ao predomínio das subpopulações de linfócitos e das alterações das citocinas na evolução da infecção parasitária, na formação do granuloma e na determinação das formas graves. Entretanto, o papel desempenhado por esses fatores na associação da esquistossomose com a salmonelose ainda é desconhecido.

$\mathrm{Na}$ fase aguda da infecção esquistossomótica predomina resposta de linfócitos T auxiliares do tipo 1, enquanto resposta de linfócitos T auxiliares do tipo 2 parece ter uma função crucial modulando a doença nas fases iniciais da oviposição do esquistossoma, embora uma resposta prolongada do tipo T auxiliar do tipo 2 possa contribuir para o desenvolvimento da fibrose hepática e para a morbidade crônica da esquistossomose ${ }^{11269496}$.

Não há consenso sobre os padrões de citocinas que determinam a evolução da esquistossomose para as formas graves. Em modelo experimental, a principal citocina que tem sido associada à fibrose hepática é a IL-13 $3^{96}$. Em seres humanos, tem sido sugerido um predomínio das citocinas T auxiliar 2, IL-4 e IL-10, nas fases iniciais da infecção. Na evolução para a cronicidade da doença, entretanto, parece haver predominância de IL-13 e possivelmente de fator de necrose tumoral e TGF- $\beta$ quando o paciente apresenta a forma hepatoesplênica da doençâ' 1112264869135 .

A evolução da esquistossomose para as formas graves depende de fatores genéticos do hospedeiro, capazes de influenciar sua reatividade imunitária e, em consequência, sua resistência à infecção e ao desenvolvimento de fibrose periportal. Também exercem influência, a carga parasitária, a intensidade e duração da infecção, presença de comorbidades, o estado nutricional do hospedeiro, oportunidades de tratamento prévio e de reinfecções ${ }^{15078}$.

A formação de granulomas ao redor dos ovos do esquistossoma no fígado dificulta progressivamente a drenagem sanguínea da veia porta, aumenta, consequentemente, a pressão venosa retrógrada e desencadeia o desenvolvimento de circulação colateral ${ }^{100}$. Com isso, parte do sangue venoso proveniente dos vasos mesentéricos passa diretamente para a circulação sistêmica sem sofrer 0 processo de filtração pelas células de Kupffer nos sinusóides hepáticos. Simultaneamente, pode ocorrer aumento progressivo do baço devido à congestão venosa e à hipercelularidade ${ }^{2}$. Portanto, o fígado e o baço, que são órgãos ricos em células do sistema fagocitário mononuclear e fundamentais na defesa do hospedeiro contra a infecção por salmonelas ${ }^{81968}$, ficam comprometidos por alterações anatômicas e funcionais importantes.

0 indivíduo esquistossomótico em contato com antígenos de salmonela desencadeia resposta imune celular específica para a bactéria. Entretanto, em casos de salmonelose septicêmica prolongada, nos quais a Salmonella typhi havia sido identificada por hemocultura, não se detectou a produção de anticorpos específicos para os antígenos $0 \mathrm{e} \mathrm{H}$ da bactéria ${ }^{90}{ }^{107}$. Gohar $^{37}$ encontrou resposta de anticorpos deprimida para o antígeno H em esquistossomóticos submetidos à vacinação antitifoídica. Esta resposta ineficaz à vacinação não foi verificada por Shikanai-Yasuda e cols ${ }^{117}$, que demonstraram eficiente formação de anticorpos para os antígenos $\mathrm{O}$ e $\mathrm{H}$ em pacientes esquistossomóticos com a forma hepatoesplênica. Rocha e cols ${ }^{108}$ demonstraram deficiência quantitativa do soro de pacientes esquitossomóticos com a forma hepatoesplênica em inibir in vitro o crescimento de salmonelas, o que não foi verificado por Mikhail e cols ${ }^{73}$ com soro de hamsters esquistossomóticos. Por outro lado, Muniz-Junqueira e cols ${ }^{80}$ encontraram em pacientes esquistossomóticos uma maior frequência de anticorpos para o antígeno 0 da Salmonella typhi, enquanto a frequência para antígenos $\mathrm{H}$ foi semelhante à observada em indivíduos normais. Entretanto, os indivíduos com a forma hepatoesplênica da doença mostraram títulos de anticorpos mais elevados para o antígeno $\mathrm{H}$ da bactéria do que os indivíduos com a forma intestinal e os não infectados. Após vacinação antitifoídica, os pacientes com a forma intestinal apresentaram menor resposta de anticorpos. Esta menor capacidade de apresentar uma resposta de anticorpos para os antígenos da Salmonella typhi poderia interferir com a depuração da bactéria da corrente sanguínea e, portanto ter um papel na sobrevida prolongada da bactéria, como observado em pacientes com a salmonelose septicêmica prolongada. Paradoxalmente, os anticorpos poderiam também ter um papel facilitador da infecção bacteriana, perpetuando a infecção por facilitar a ingestão da bactéria por fagócitos com os mecanismos microbicidas deprimidos.

A reação inflamatória local, avaliada por meio da janela cutânea de Rebuck e Crowley modificada, mostrou-se retardada e deprimida em pacientes esquistossomóticos com a forma hepatoesplênica ${ }^{29115}$. A depressão ocorreu tanto com as linhagens de células polimorfonucleares, quanto mononucleares ${ }^{29}$. Animais esquistossomóticos mostram maior susceptibilidade e maior mortalidade à infecção por salmonelas ${ }^{6383}{ }^{106}$, estando normal a depuração das bactérias da corrente sanguínea ${ }^{109}$. No entanto, ocorre multiplicação bacteriana em maior número ${ }^{106}$ e por tempo mais prolongado ${ }^{110}$ no fígado e no baço dos animais esquistossomóticos, acompanhada por reinvasão circulatória mais intensa, comparativamente aos animais normais. Essas observações sugerem que o sistema fagocítico mononuclear dos animais esquistossomóticos, embora conserve sua capacidade fagocitária, apresenta dificuldade para destruir a bactéria após a fagocitose $\mathrm{e}^{99}$ ${ }^{109}$. Porém, a avaliação in vitro da fagocitose pelos macrófagos peritoneais de camundongos esquistossomóticos mostraram reduzida capacidade para fagocitar Salmonella typhimurium, pelo menor envolvimento de macrófagos na fagocitose, como 
também uma reduzida capacidade microbicida destas células, enquanto que 0 número de partículas ingeridas por cada macrófago estava preservada $^{7879}$. As Figuras 1, 2, 3 e 4 mostram, respectivamente, os aspectos da fagocitose de Salmonella typhimurium por macrófagos peritoneais de camundongos normais, infectados cronicamente por Schistosoma mansoni, infectados há uma semana por Salmonella typhimurium e coinfectados cronicamente por Schistosoma mansoni e há uma semana por Salmonella typhimurium. Pode ser observado que os animais previamente infectados com a salmonela fagocitam intensamente a bactéria (Figura 3). Os macrófagos dos animais coinfectados por salmonela e esquistossoma mostraram uma menor reserva na capacidade fagocitária, pois foram incapazes de aumentar a fagocitose pelo aumento da carga bacteriana, sugerindo que os macrófagos dos animais esquistossomóticos já se encontram em seu limite funcional de atividade ${ }^{80}$, além de serem incapazes de destruir a bactéria após a fagocitose ${ }^{79}, 0$ que pode facilitar o desenvolvimento da forma crônica da salmonelose pela incapacidade de contenção do microorganismo.

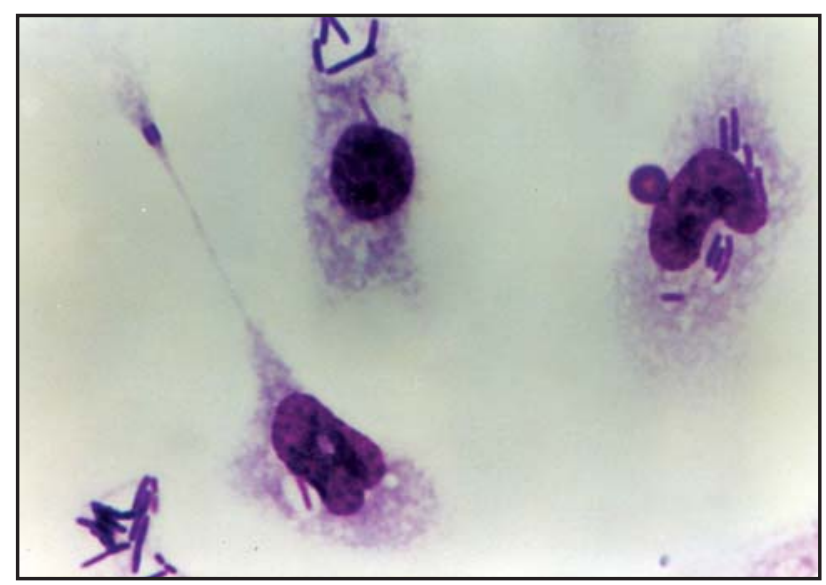

\section{FIGURA 1}

Macrófagos peritoneais de camundongo sadio CD1 (Charles River) incubados in vitro com Salmonella typhimurium na presença de soro imune. Nota-se a presença de vacúolos fagocíticos bem delimitados contendo salmonelas e um macrófago lançando pseudópode para captar a bactéria. Coloração por Giemsa; aumento de 1000X.

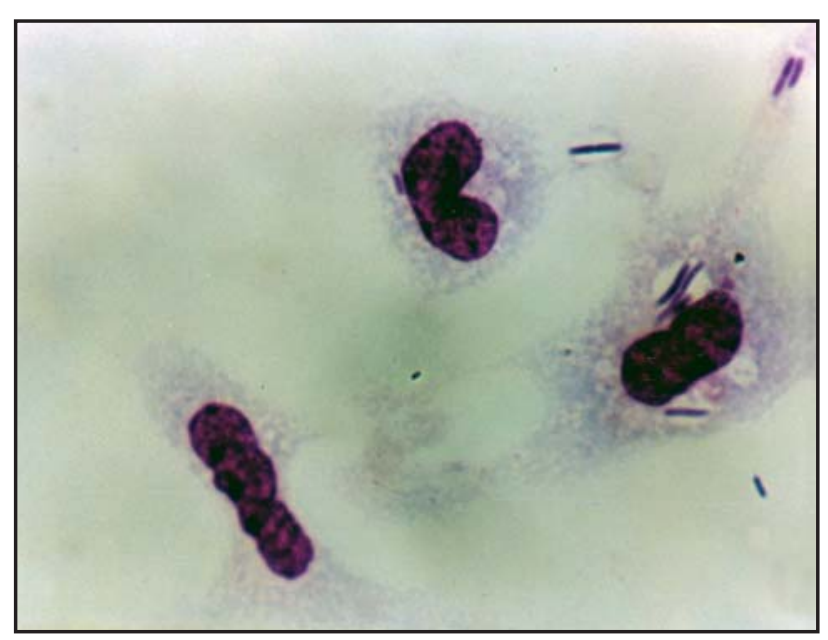

FIGURA 2

Fagocitose in vitro de Salmonella typhimurium por macrófagos peritoneais de camundongo CD1 (Charles River) infectado há 4 meses com Schistosoma mansoni, na presença de soro imune. Observe os vacúolos fagocíticos bem delimitados. Coloração por Giemsa; aumento de 1000X.

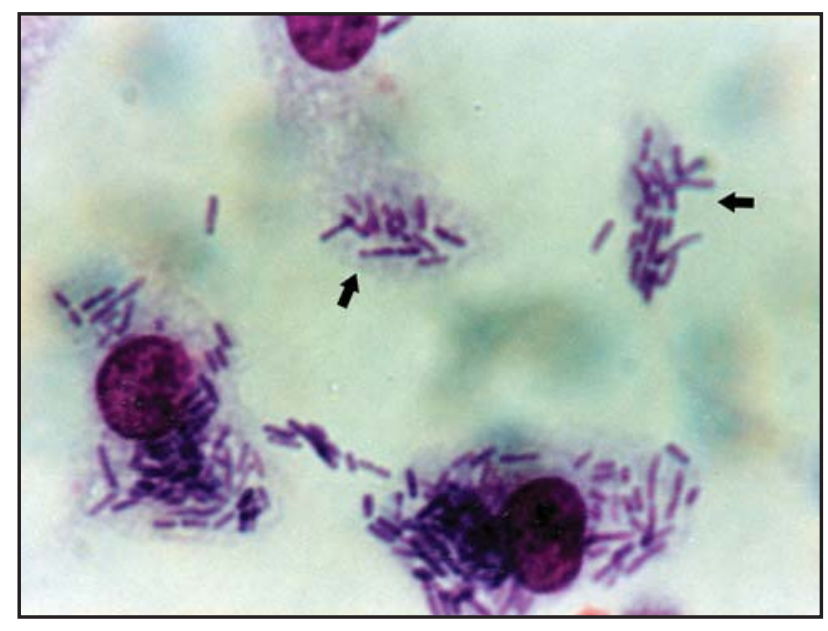

FIGURA 3

Fagocitose in vitro, na presença de soro imune, de grande quantidade de Salmonella typhimurium por macrófagos peritoneais de camundongo CD1 (Charles River), infectado há 7 dias com $1,5 \times 10^{5}$ unidades formadoras de colônias da mesma bactéria. Observe a distribuição polar (seta) sugerindo fagocitose recente, e a distribuição esparsa pelo citoplasma nos outros macrófagos. Coloração por Giemsa; aumento de $1000 \mathrm{X}$

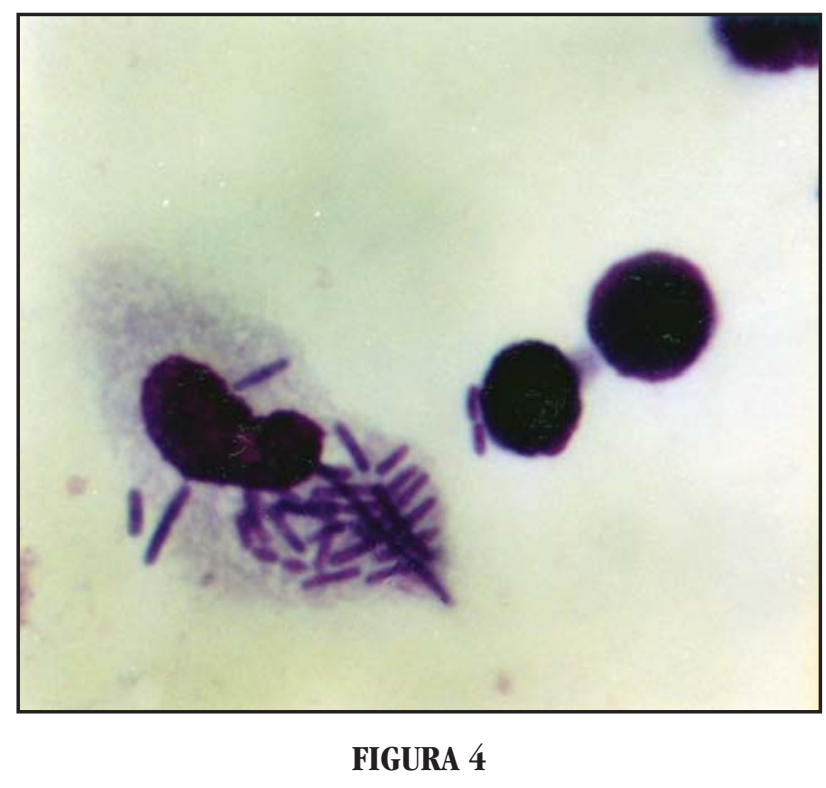

Macrófago peritoneal de camundongo CD1 (Charles River) infectado há 4 meses com Schistosoma mansoni e coinfectado há 7 dias com 1,5x10 unidades formadoras de colônias de Salmonella typhimurium fagocitando in vitro grande quantidade de salmonelas na presença de soro imune. Coloração por Giemsa; aumento de 1000X.

As funções fagocitária e microbicida dos macrófagos são tão fundamentais para a defesa do organismo que estas células possuem vários mecanismos alternativos que se completam e funcionam concomitantemente, como enzimas proteolíticas, acidificação do fagolisossoma, peptídeos catiônicos, proteínas que ligam ferro, e radicais de oxigênio e nitrogênio para destruir os microorganismos fagocitados ${ }^{73131}$. Os patógenos que conseguem escapar desses mecanismos microbicidas se encontram em situação privilegiada, podendo sobreviver, multiplicar-se e levar a alterações patológicas crônicas. 
Estudos in vivo e in vitro sugerem que na esquistossomose crônica aproximadamente $40 \%$ dos macrófagos não conseguem fagocitar e entre os que fagocitam, ocorre deficiência acentuada da capacidade de destruição das bactérias, indicando a possibilidade de a salmonela sobreviver e multiplicar-se no citoplasma dos macrófagos, levando a um quadro de ativação crônica do sistema fagocítico que caracteriza a salmonelose septicêmica prolongada $^{79}$.

Em conclusão, os fatores determinantes do quadro da salmonelose septicêmica prolongada são vários e dependem da interação peculiar entre a bactéria e o parasito, como também das características do sistema imunitário do hospedeiro modificada em consequência da infecção crônica pelo esquistossoma que resulta em alterações da produção de anticorpos, da resposta imunitária celular e das alterações do sistema de fagócitos levando consequentemente à persistência da bactéria e à evolução crônica da síndrome de septicemia.

\section{AGRADECIMENTOS}

Os autores agradecem à Sra. Fernanda Muniz Junqueira Ottoni e Sr. Paulo Hipólito Bezerra Leite, pela editoração das ilustrações.

\section{REFERÊNCIAS}

1. Abath FGC, Morais CNL, Montenegro CE, Wynn TA, Montenegro SML. Immunopathogenic mechanisms in schistosomiasis: what can be learnt from human studies? Trends in Parasitology 22: 85-91, 2006.

2. Andrade ZA, Andrade SG. Patologia do baço na esquistossomose hepatoesplênica. Revista do Instituto de Medicina Tropical de São Paulo 7: 218-227, 1965.

3. Andrade ZA, Warren KS. Mild prolonged schistosomiasis in mice: alteration in host response with time and the development of portal fibrosis. Transactions of the Royal Society of Tropical Medicine and Hygiene 58: 53-57, 1964.

4. Attallah AM, Smith AH, Murrell KD, Fleischer T, Woody J, Vanier WE, Scher I, Ahmed A, Sell KW. Characterization of the immunosuppressive state during Schistosoma mansoni infection. Journal of Immunology 122: 1413-1420, 1979

5. Barsoun IS, Gamil FM, Al-Khafif MA. Ramzy RM, El Alamy MA, Colley DG. Immune response and immuneregulation in relation to human schistosomiasis in Egypt. I. Effect of treatment on in vitro cellular responsiveness. The American Journal of Tropical Medicine and Hygiene 31: 1181-1187, 1982.

6. Bastos OC, Rangel HA, Magalhães LA, Piedrabuena AE. Evolução das imunoglobulinas envolvidas na resposta imune de camundongos ao Schistosoma mansoni. Revista de Saúde Pública de São Paulo 18: 138-154, 1984.

7. Bianco C, Griffin Jr FM, Silverstein SC. Alteration of the macrophage complement receptor. Alteration of receptor function upon macrophage activation. Journal of Experimental Medicine 141: 1278-1290, 1975.

8. Blanden RV, Mackaness GB, Collins FM. Mechanisms of acquired resistance in mouse typhoid. Journal of Experimental Medicine 124: 585-600, 1966.

9. Boros DL, Pelley RP, Warren KS. Spontaneous modulation of granulomatous hypersensitivity in schistosomiasis mansoni. Journal of Immunology 114: 14371441, 1975.

10. Bouillard C, Miegeville M, Vermeil C. Études in vivo et in vitro des relations entre Schistosoma mansoni et certaines souches d'entérobacterias. Bulletin de la Société de Pathologie Exotique 75: 426-433, 1982.

11. Burke ML, Jones MK, Gobert GN, Ly YS, Ellis MK, McManus DP. Immunopathogenesis of human schistosomiasis. Parasite Immunology 31: 163-176, 2009.
12. Caldas IR, Campi-Azevedo AC, Oliveira LFA, Silveira AMS, Oliveira RC, Gazzinelli G. Human schistosomiasis mansoni: Immune responses during acute and chronic phases of the infection. Acta Tropica 108:109-117, 2008.

13. Camus D, Carlier Y, Capron M, Bina JC, Figueiredo JF, Prata A, Capron A. Immunological studies in human schistosomiasis. III. Immunoglobulin levels, antibodies, and delayed hypersensitivity. The American Journal of Tropical Medicine and Hygiene 26: 482-490, 1977.

14. Capron A, Dessaint JP. Effector and regulatory mechanisms in immunity to schistosomes: A heuristic view. Annual Review of Immunology 3: 455-476, 1985.

15. Capron A, Dessaint JP, Capron M, Joseph M, Torpier G. Effector mechanisms of immunity to schistosomes and their regulation. Immunological Reviews 61: 41-66, 1982.

16. Cherubin CE, Neu HC, Imperato PJ, Harvey RP, Bellen N. Septicemia with nontyphoid Salmonella. Medicine 53: 365-376, 1974.

17. Coelho PMZ, Mayrink W, Dias M, Pereira LH. Susceptibility to Leishmania mexicana of mice infected with Schistosoma mansoni. Transactions of the Royal Society of Tropical Medicine and Hygiene 74: 141, 1980.

18. Colley DG, Todd CW, Lewis FA, Goodgame RW. Immune responses during human schistosomiasis mansoni. VI. In vitro nonspecific suppression of phytohemagglutin responsiveness induced by exposure to certain schistosomal preparations. Journal of Immunology 122: 1447-1453, 1979.

19. Collins FM, Mackaness GB, Blanden V. Infection-immunity in experimental salmonellosis. Journal of Experimental Medicine 124: 601-619, 1966.

20. Conn HO, Fessel JM. Spontaneous bacterial peritonitis in cirrhosis: variation on a theme. Medicine 50: 161-197, 1971.

21. Cottrell BJ, Humber D, Sturrock RF, Seitz H, Rees P. Non-specific cell mediated immunity in patients infected with Schistosoma mansoni in Kenya. Transactions of the Royal Society of Tropical Medicine and Hygiene 78: 234-237, 1982.

22. Coutinho AD, Antunes MTA, Domingues ALC. Estudo da imunidade humoral e celular na doença hepática esquistossomótica. Revista do Instituto de Medicina Tropical de São Paulo 24: 282-291, 1982.

23. Dale DC, Boxer L, Liles WC. The phagocytes: neutrophils and monocytes. Blood 112: 935-945, 2008.

24. Delaunay-Chaillou MD, Miegeville M, Vermeil C. Essais de mise en évidence des relations Schistosomes-Salmonelles. Études in vivo et in vitro. Bulletin de la Société de Pathologie Exotique 75: 183-191, 1982.

25. Dessaint JP, Capron M, Bout D, Capron A. Quantitative determination of specific IgE antibodies to schistosome antigens and serum IgE levels in patients with schistosomiasis (S. mansoni or S. haematobium). Clinical and Experimental Immunology 20: 427-436, 1975.

26. Dune DW, Pearce EJ. Immunology of hepatosplenic schistosomiasis mansoni: a human perspective. Microbes and Infection 1: 553-560; 1999.

27. Edelman R, Levine MM. Summary of an international workshop on typhoid fever. Review of Infectious Diseases 8: 329-349, 1986.

28. Ellner JJ, Olds GR, Osman GS, El Kholy A, Mahmoud AAF. Dichotomies in the reactivity to worm antigen in human schistosomiasis mansoni. Journal of Immunology 126: 309-312, 1981.

29. Fernandes DJ, Rocha H. Características da reação inflamatória em pacientes com forma hepatoesplênica de esquistossomose mansônica e calazar. Revista do Instituto de Medicina Tropical de São Paulo 9: 129-134, 1967.

30. Ferreira JM. Febre tifóide. Revista de Medicina 38: 181-198, 1954.

31. Ferreira JM, Bassoi ON, Shiroma M. Salmonelose de curso prolongado associada à esquistossomose mansônica hepatoesplênica. Análise de 7 casos. Revista do Hospital das Clínicas da Faculdade de Medicina da Universidade de São Paulo 31: 144-150, 1976.

32. Fischi MA, Dickison GM, Sinaue C, Pitchenik AE, Cleary TJ. Salmonella bacteremia as manifestation of acquired immunodeficiency syndrome. Archives of Internal Medicine 146: 113-115, 1986.

33. Gazzinelli G, Katz N, Rocha RS, Colley DG. Immune responses during human schistosomiasis mansoni. VIII. Differential in vitro cellular responsiveness to adult worm and schistosomular tegumental preparation. The American Journal of Tropical Medicine and Hygiene 32: 326-333, 1983.

34. Gazzinelli G, Montesano MA, Correa-Oliveira R, Souza-Lima M, Katz N, Rocha RS, Colley DG. Immune response in different clinical groups of schistosomiasis patients. Memórias do Instituto Oswaldo Cruz 82: 95-100, 1987. 
35. Gendrel D, Kombila M, Beaudoin-Leblevec G, Richard-Lenoble D. Nontyphoidal salmonella septicemia in Gabonese children infected with Schistosoma intercalatum. Clinical Infectious Diseases 18:103-105,1994.

36. Gendrel D, Richard-Lenoble D, Kombila M. Engohan E, Nardou M, Moussavou A, Galliot A, Toure R. Schistosoma intercalatum and relapses of Salmonella infection in children. The American Journal of Tropical Medicine and Hygiene 33: 1166-1169, 1984.

37. Gohar MA, Eissa AA, Sebai I. Antibody response in Egyptian splenomegaly. The American Journal of Tropical Medicine and Hygiene 31: 605-610, 1951.

38. Gordon MA. Salmonella infections in immunocompromised adults. Journal of Infection 56: 413-422, 2008.

39. Halawani A, Abdalla A, Badran A. The relation between schistosomiasis and the urinary Salmonella carrier state. The American Journal of Tropical Medicine and Hygiene 9: 371-373, 1960.

40. Han T, Sokal JE, Netter E. Salmonellosis in disseminated malignant diseases. New England Journal of Medicine 276: 1045-1052, 1967.

41. Hathout SED, El-Ghaffar YA, Awny AY. Salmonellosis complicating schistosomiasis in Egypt. A new clinical appreciation. The American Journal of Tropical Medicine and Hygiene 16: 462-472, 1967.

42. Hathout SED, El-Ghaffar YA, Awny AY, Hassan K. Relation between urinary schistosomiasis and chronic enteric urinary carrier state among Egyptians. The American Journal of Tropical Medicine and Hygiene 15: 156-161, 1966.

43. Higashi GI. The interaction of Schistosoma and bacterial infections. World Health Organization. Expert Committee on the Control of Schistosomiasis, Geneva 8-13 november/SCH/EC/WP/84.30, 1984.

44. Hornick RB. Non-typhoid salmonellosis. In: Hoeprich PD (ed) Infectious Diseases, third edition, Harper and Row, Philadelphia, p. 655-661, 1983.

45. Hornick RB. Selective primary health care. Strategies for control of disease in developing world. XX. Typhoid fever. Review of Infectious Diseases 7: 536-546, 1985.

46. Hornick RB, Greisman SE, Woodward TE, Dupont HL, Dawkins AT, Snyder MJ. Typhoid fever: pathogenesis and immunologic control. New England Journal of Medicine 283: 739-746, 1970.

47. Hsu HS, Radcliffe AS. Interactions between macrophages of guinea pigs and Salmonellae. I: Fate of Salmonella typhimurium within macrophages of normal guinea pigs. Journal of Bacteriology 96: 191-197, 1968.

48. Jesus AR, Magalhães A, Miranda DG, Miranda RG, Araújo MI, de Jesus AA, Silva A, Santana LB, Pearce E, Carvalho EM. Association of type 2 cytokines with hepatic fibrosis in human Schistosoma mansomi infection. Infection and Immunity 72 : 3391-3397, 2004

49. Jones CE, Rachford FW, Ali Özcell M, Lewert RM. Schistosoma japonicum: semiquantitative assessment of circulating immune complexes, serum $\mathrm{C1q}$ and $\mathrm{C} 3$, and their relationship to renal pathology and hepatic fibrosis in rabbits. Experimental Parasitology 42: 221-234, 1977.

50. King CH, Dangerfield-Cha M. The unacknowledged impact of chronic schistosomiasis. Chronic Illness 4: 65-79, 2008

51. Kita E, Emoto M, Yasui K, Yasui K, Katsui N, Nishi K, Kashiba S. Cellular aspects of the longer-lasting immunity against mouse typhoid infection afforded by live-cell and ribossomal vaccines. Immunology 57: 431-435, 1986.

52. Kloetzel K, Faleiros JJ, Mendes SR, Stanley CT, Arias HS. Concomitant infection of albino mice by Trypanosoma cruzi and Schistosoma mansoni. Parasitological parameters. Transactions of the Royal Society of Tropical Medicine and Hygiene 67: 652-658, 1973

53. Kloos H, Correa-Oliveira R, Quites HFO, Souza MCC, Gazzinelli A. Socioeconomic studies of schistosomiasis in Brazil: A review. Acta Tropica 108:194-201, 2008.

54. Knight R, Warren KS. The interaction between Entamoeba histolytica and Schistosoma mansoni infections in mice. Transactions of the Royal Society of Tropical Medicine and Hygiene 67: 644-651, 1973.

55. Krakower C, Hoffman WA, Axtmayer JH. The fate of schistosomes (S. mansoni) in experimental infections of normal and vitamin A deficient white rats. The Puerto Rico Journal of Public Health and Tropical Medicine 16: 269-345, 1940.

56. Lambertucci JR, Marinho RP, Ferreira MD, Neves J, Pedroso ER. Therapeutic efficacy of oral oxamniquine in the treatment of prolonged septicemic salmonellosis. Revista do Instituto de Medicina Tropical de São Paulo 27: 33-39, 1985.
57. Lambertucci JR, Rayes AAM, Serufo JC, Gerspacher-Lara R, Brasileiro-Filho G, Teixeira R, Antunes CMF, Goes AM, Coelho PMZ. Schistosomiasis and associated infections. Memórias do Instituto Oswaldo Cruz 93 (supl I): 135-139, 1998.

58. Lambertucci JR, Serufo JC, Gerspacher-Lara R, Rayes AAM, Teixeira R, Nobre V, Antunes CMF. Schistosoma mansoni: assessment of morbidity before and after control. Acta Tropica 77: 101-109, 2000.

59. Lambertucci JR, Silva LCS, Voieta I. Esquistossomose mansônica. In: Coura JR (ed) Dinâmica das Doenças Infecciosas e Parasitárias, Guanabara Koogan, Rio de Janeiro, p. 931-946, 2005.

60. Laughlin LW, Farid Z, Mansour N, Edman DC, Higashi GI. Bacteriuria in urinary schistosomiasis in Egypt. A prevalence survey. The American Journal of Tropical Medicine and Hygiene 27: 916-918, 1978.

61. Lawley TJ, Ottensen EA, Hiatt RA, Gazze LA. Circulating immune complexes in acute schistosomiasis. Clinical and Experimental Immunology 37: 221-227, 1979.

62. Lehman Jr JS, Farid Z, Smith JH, Bassily S, El-Masry NA. Urinary schistosomiasis in Egypt: clinical, radiological, bacteriological and parasitological correlations. Transactions of the Royal Society of Tropical Medicine and Hygiene 67: 384-399, 1973.

63. Lima DB, Pessoa MHR, Suassuna I. I. Modelo de esquistossomose crônica, em camundongo, para estudo da interação com salmonelose. Revista Lationoamericana de Microbiologia 24: 273-280, 1982.

64. Lissner CR, Swanson RN, O'Brien AD. Genetic control of the innate resistance of mice to Salmonella typhimurium: expression of the Ity gene in peritoneal and splenic macrophages isolated in vitro. Journal of Immunology 131: 3006-3013, 1983.

65. Lo Verde PT, Amento C, Higashi GI. Parasite-parasite interaction of Salmonella typhimurium and Schistosoma. Journal of Infectious Diseases 141: 177-185, 1980 .

66. Macedo V, Bina JC, Prata A. Tratamento da salmonelose de curso prolongado com Hycanthone. Gazeta Médica da Bahia 3: 194-199, 1970.

67. Machado JAM, Silva EN, Katz N, Rocha RS, Gazzinelli G. Peripheral lymphocytes in patients with intestinal schistosomiasis mansoni. Transactions of the Royal Society of Tropical Medicine and Hygiene 72: 441, 1978.

68. Mackaness GB, Blanden RV, Collins FM. Host-parasite relations in mouse typhoid. Journal of Experimental Medicine 124: 573-583, 1966.

69. Magalhães A, Miranda DG, Miranda RG, Araújo MI, Jesus AA, Silva A, Santana LB, Pearce E, Carvalho EM, Jesus AR. Cytokine profile associated with human chronic schistosomiasis mansoni. Memórias do Instituto Oswaldo Cruz 99 ( $\operatorname{supl}$ I): 21-26, 2004.

70. Mahmoud AAF. Schistosomiasis. In: Gilles HM (ed) Recent advances in Tropical Medicine, Churchill Livingstone, London, p. 179-206, 1984.

71. Melhem RF, Lo Verde PT. Mechanism of interaction of Salmonella and Schistosoma species. Infection and Immunity 44: 274-281, 1984.

72. Mendes E, Mendes NF. High levels of IgE in patients with schistosomiasis mansoni. Quantification of total and specific IgE and IgG. Tropical and Geographic Medicine 34: 133-137, 1982.

73. Mikhail IA, Higashi GI, Edman DC, Elwan SH. Interaction of Salmonella paratyphi A and Schistosoma mansoni in hamsters. The American Journal of Tropical Medicine and Hygiene 31: 328-334, 1982.

74. Mitsuhashi S, Sato I, Tanaka T. Experimental salmonelosis. Intracellular growth of Salmonella enteriditis ingested in mononuclear phagocytes of mice, and cellular basis of immunity. Journal of Bacteriology 81: 863-868,1961.

75. Moellering RC, Weinberg AN. Persistent Salmonella infection in a female carrier of chronic granulomatous disease. Annals of Internal Medicine 73: 595-601, 1970 .

76. Mota-Santos TA, Gazzinelli G, Ramalho-Pinto FJ, Pellegrino J, Silva WD. Immunodepression in mice following Schistosoma mansoni infection. . Revista do Instituto de Medicina Tropical de São Paulo 18: 246-250, 1976.

77. Mota-Santos TA, Tavares CAP, Gazzinelli G, Pellegrino J. Immunosuppression mediated by adult worms in chronic schistosomiasis mansoni. The American Journal of Tropical Medicine and Hygiene 26: 727-731,1977.

78. Muniz-Junqueira MI. Reposta imune e atividade de macrófagos para Salmonella na esquistossomose mansoni. Tese, Universidade de Brasília, Brasília, DF, 1987. 
79. Muniz-Junqueira MI, Prata A, Tosta CE. Phagocytic and bactericidal function of mouse macrophages to Salmonella typhimurium in schistosomiasis mansoni. The American Journal of Tropical Medicine and Hygiene 46: 132-136, 1992.

80. Muniz-Junqueira MI, Prata A, Tosta CE. Factors influencing phagocytosis of Salmonella typhimurium by macrophages in murine schistosomiasis. Revista da Sociedade Brasileira de Medicina Tropical 30: 101-106, 1997.

81. Muniz-Junqueira MI, Tavares-Neto, Ataide M, Prata A, Tosta CE. Specific treatment of hepatosplenic schistosomiasis can increase T-lymphocyte reactivity. Revista da Sociedade Brasileira de Medicina Tropical 24: 97-99, 1991.

82. Muniz-Junqueira MI, Tavares-Neto J, Prata A, Tosta CE. Antibody response to Salmonella typhi in human schistosomiasis mansoni. Revista da Sociedade Brasileira de Medicina Tropical 29: 441-445, 1996.

83. Muniz-Junqueira MI, Tosta CE, Prata A. T cell-dependent immunodepression in vivo in Schistosoma mansoni-infected patients. Revista da Sociedade Brasileira de Medicina Tropical 23: 27-31, 1990.

84. Muniz-Junqueira MI, Tosta CE, Prata A. Existe forma subclínica de salmonelose septicêmica prolongada? Revista da Sociedade Brasileira de Medicina Tropical 24: 90, 1991.

85. Nadelman RB, Mathur-Wagh U, Yancovitz SR, Mildvan D. Salmonella bacteremia associated with acquired immunodeficiency syndrome (AIDS). Archives of Internal Medicine 145: 1968-1971, 1985.

86. Nash TE, Ottesen EA, Cheever AW. Antibody responses to a polysaccharide antigen present in the schistosome gut. II. Modulation of antibody response. The American Journal of Tropical Medicine and Hygiene 27: 944-950, 1978.

87. Neves J. Salmonelose septicêmica prolongada em face às doutrinas de Kiel e de Montevidéu. Revista da Sociedade Brasileira de Medicina Tropical 1: 59-68, 1967.

88. Neves J. Salmonelose septicêmica prolongada. Jornal Brasileiro de Medicina 15: $247-259,1968$

89. Neves J, Martins NRL. Salmonelose septicêmica prolongada. Subsídio à sua patogenia. Revista do Instituto de Medicina Tropical de São Paulo 7: 233-240, 1965.

90. Neves J, Martins NRL. Long duration of septicaemic salmonellosis: 35 cases with 12 implicated species of Salmonella. Transactions of the Royal Society of Tropical Medicine and Hygiene 61: 541-552, 1967.

91. O'Brien AD. Innate resistance of mice to Salmonella typhi infection. Infection and Immunity 38: 948-952,1982.

92. O'Brien AD, Metcalf ES. Control of early Salmonella typhimurium growth in innately Salmonella-resistant mice does not require functional T lymphocytes. Journal of Immunology 129: 1349-1351, 1982.

93. Olds GR, El Kholy A, Ellner JJ. Two distinctive patterns of monocyte immunoregulatory and effector functions in heavy human infections with Schistosoma mansoni. Journal of Immunology 131: 954-958, 1983.

94. Oliveira-Prado R, Caldas IR, Teixeira-Carvalho A, Andrade MV, Gazzinelli A, Correa-Oliveira R, Cunha-Melo JR. $\mathrm{CD}^{+}$and $\mathrm{CD}^{+}$distribution profile in individuals infected by Schistosoma mansoni. Clinical Immunology 69: 521528,2009 .

95. Ottens H, Dickerson G. Studies on the effects of bacteria on experimental schistosomiasis infections in animals. Transactions of the Royal Society of Tropical Medicine and Hygiene 66: 85-107, 1972.

96. Pearce EJ, MacDonald AS. The immunobiology of schistosomiasis. Nature Reviews Immunology 2: 499- 511, 2002.

97. Pelley RP, Ruffier JJ, Warren KS. Suppressive effect of a chronic helminth infection, schistosomiasis mansoni, on the in vitro responses of spleen and lymph node cells to the T cell mitogens phytohemagglutinin and concanavalin A. Infection and Immunity 13: 1176-1183, 1976.

98. Plant J, Glyn AA. Genetics of resistance to infection with Salmonella typhimurium in mice. Journal of Infectious Diseases 133: 72-78, 1976.

99. Prata A. Patogenia da febre tifóide prolongada. Gazeta Médica da Bahia 69: 111-112, 1969

100. Prata A. Schistosomiasis mansoni. Clinics in Gastroenterology 7: 49-74, 1978.

101. Prata A. Esquistossomose mansoni. In: Veronesi R (ed) Doenças Infecciosas e Parasitárias, Guanabara Koogan, Rio de Janeiro, p. 884-904, 1982.

102. Prata A. Infection with $S$. mansoni. In: Jordan P, Webbe G (eds) Schistosomiasis. Epidemiology, treatment and control. Heinemann Medical Books, London, p. $105-127,1982$
103. Rajagopalan P, Kumar R, Malaviva N. Immunological studies in typhoid fever. I. Immunoglobulins, C3, antibodies, rheumatoid factor and circulating immune complexes in patients with typhoid fever. Clinical and Experimental Immunology 44: 68-73, 1981.

104. Rajagopalan P, Kumar R, Malaviya N. Immunological studies in typhoid fever. II. Cellular immune responses and lymphocyte subpopulations in patients with typhoid fever. Clinical and Experimental Immunology 47: 269-274, 1982

105. Rocha H. Aspectos da interação do $S$. mansoni com bactérias do gênero Salmonella. In: Aspectos peculiares da infecção pelo Schistosoma mansoni Centro de Estudos de Doenças Regionais (CEDRE), Centro Editorial e Didático da Universidade Federal da Bahia, Salvador, p. 65-74, 1984.

106. Rocha H, Castilho EA, Barreto AC, Hook EW. Características da infecção por S. typhimurium em camundongos infectados com $S$. mansoni. Gazeta Médica da Bahia 68: 6-18, 1968

107. Rocha H, Kirk JW, Hearey CD. Prolonged Salmonella bacteremia in patients with Schistosoma mansoni infection. Archives of Internal Medicine 128: 254-257, 1971.

108. Rocha H, Magnavita M, Teles ES, Rebouças G. Atividade antibacteriana do soro de pacientes com a forma hepatoesplênica da esquistossomose mansônica. Revista do Instituto de Medicina Tropical de São Paulo 10: 364-370, 1968

109. Rocha H, McCrory M, Oliveira MMG. Início da infecção por S. typhimurium em camundongos com esquistossomose mansônica. Revista do Instituto de Medicina Tropical de São Paulo 13: 328-332, 1971.

110. Rocha H, Oliveira MMG, Oliveira VS, Prata A. Algumas características da infecção por Salmonella typhi em camundongos com esquistossomose experimental: multiplicação da bactéria no Schistosoma mansoni. Revista do Instituto de Medicina Tropical de São Paulo 13: 399-404, 1971.

111. Rocha H, Oliveira VS, Oliveira MMG. The interaction of Gram-negative bacteria and $S$. manson $i$ in mice with experimental schistosomiasis. Memórias do Instituto Oswaldo Cruz 75: 161-172, 1980.

112. Rocklin RE, Brown AP, Warren KS, Pelley RP, Houba V, Siongok TKA, Ouma J, Sturrock RF, Butterworth AE. Factors that modify the cellular-immune response in patients infected by Schistosoma mansoni. The Journal of Immunology 125: 1916-1923, 1980.

113. Salam EA, Higashi GI, Kamal KA, Ishaac S. Cell-mediated immune assav in children with Schistosoma haematobium infection and the effect of niridazole therapy. Transactions of the Royal Society of Tropical Medicine and Hygiene 75: 207-214, 1981

114. Samra Y, Shaked Y, Maier MK. Nontyphoid salmonellosis in renal transplant recipients: report of five cases and review of the literature. Reviews of Infectious Diseases 8: 431-440, 1986

115. Schiller CF, Fernandez DJ, Rocha H. Reação inflamatória local de pacientes com esquistossomose mansônica antes e após esplenectomia. Gazeta Médica da Bahia 66: 76-81, 1966

116. Serufo JC, Lambertucci JR. Esquistossomose e hepatites virais: uma revisão. Revista da Sociedade Brasileira de Medicina Tropical 30:313-322, 1997.

117. Shikanai-Yasuda MA, Yasuda PH, Ferri RG, Castilho EA, Shiroma M. Resposta imune humoral à vacina antitifoídica em esquistossomose mansônica hepatoesplênica. Revista do Instituto de Medicina Tropical de São Paulo 24: 198-204, 1982

118. Silveira AM, Gazzinelli G, Alves-Oliveira LF, Bethony J, Gazzinelli A, CarvalhoQueiroz C, Alvarez MC, Lima-Silva FC, Prata A, LoVerde PT, Correa-Oliveira R. Human schistosomiasis mansoni: intensity of infection differentially affects the production of interleukin-10, interferon-gamma and interleukin- 13 by soluble egg antigen or adult worm antigen stimulated cultures. Transactions of the Roval Society of Tropical Medicine and Hygiene 98: 514-519, 2004.

119. Skamene E, Gros P, Forget A, Kongshavn PAL, Charles CS, Taylor BA. Genetic regulation of resistance to intracellular pathogens. Nature 297: 506-509, 1982

120. Smith MD, Verroust PJ, Morel-Moroger L. A study of the presence of circulating immune complexes in schistosomiasis. Transactions of the Royal Society of Tropical Medicine and Hygiene 71: 343-348, 1977.

121. Smith RA, Bigley NJ. Detection of delayed hypersensitivity in mice injected with ribonucleic acid-protein fractions of Salmonella typhimurium. Infection and Immunity 6: 384-389, 1972. 
122. Smithers SR, Doenhoff MK. Schistosomiasis. In: Cohen S, Warren KS (eds) Immunology of Parasitic Infections, Blackwell Scientific Publications, Boston, p. 527-607, 1982.

123. Swanson RN, O'Brien AD. Genetic control of the innate resistance of mice to Salmonella typhimurium. Ity gene is expressed in vivo by 24 hours after infection. Journal of Immunology 131: 3014-3020, 1983.

124. Tai TY, Hsu CY, Chang HC, Liu YK. Typhoid and paratyphoid fevers occurring in cases of schistosomiasis. Chinese Medical Journal 76:426-435, 1958.

125. Teixeira RS. Estudo clínico de casos de febre tifóide prolongada. Tese de Doutorado, Universidade Federal da Bahia, Salvador, Bahia, 1959.

126. Teixeira RS. A febre tifóide de curso prolongado e o calazar: estudo comparativo. O Hospital 63: 165-186, 1963.

127. Teixeira RS. Associação da infecção por $S$. mansoni e bacteremia prolongada por enterobactérias. In: Aspectos peculiares da infecção pelo Schistosoma mansoni. Centro de Estudos de Doenças Regionais (CEDRE), Centro Editorial e Didático da Universidade Federal da Bahia, Salvador, p. 35-102, 1984.

128. Teixeira RS. Enterobacteriose septicêmica prolongada. In: Focaccia R (ed) Veronesi Tratado de Infectologia, terceira edição, Editora Atheneu, São Paulo, p. 853-860, 2005.

129. Teixeira R, Bina JC, Barreto SH. Septicemia prolongada por bactéria do gênero Escherichia em paciente com esquistossomose mansônica. Revista Médica da Bahia 22: 70-74, 1976.

130. Tuazon CCU, Nash T, Cheever A, Neva F, Lininger L. Influence of Salmonella bacteremia on the survival of mice infected with Schistosoma mansoni. Journal of Infectious Diseases 151: 1166-1167, 1985.
131. Underhill DM, Ozinsky A. Phagocytosis of microbes: complexity in action. Annual Review of Immunology 20: 825-852, 2002.

132. Warren JW, Hornick RB. Immunization against typhoid fever. Annual Review of Medicine 30: 457-472, 1979.

133. Warren KS. The secret of the immunopathogenesis of schistosomiasis: in vivo model. Immunological Reviews 61: 189-213,1982.

134. Weinstein DL, Carsiotis M, Lissner CR, O'Brien AD. Flagella help Salmonella typhimurium survive within murine macrophages. Infection and Immunity 46 : 819-825, 1984.

135. Wilson MK, Mentink-Kane M, Pesce JT, Ramalingam TR, Thompson R, Wynn TA. Immunophatology of schistosomiasis. Immunology and Cell Biology 85: 148-154; 2007.

136. Wolfe MS. Armstrong D, Louria DB, Blevins A. Salmonellosis in patients with neoplastic disease. Archives of Internal Medicine 128: 546-554, 1971.

137. World Health Organization. The control of schistosomiasis. Technical Report Series 728, 1985.

138. Yoeli M. Some aspects of concomitant infections of plasmodia and schistosomes. I. The effect of Schistosoma mansoni on the course of infection of Plasmodium berghe $i$ in the field vole (Microtus guentheri). The American Journal of Tropical Medicine and Hygiene 5: 988-999, 1956.

139. Young SW, Higashi G, Kamel R, Abdin AZ, Mikhail IA. Interaction of salmonellae and schistosomes in host-parasite relations. Transactions of the Royal Society of Tropical Medicine and Hygiene 67: 979-802, 1973.

140. Zhang X-L, Jeza VT, Pan Q. Salmonella typhi: from a human pathogen to a vaccine vector. Cellular and Molecular Immunology 5: 91-97, 2008. 